\title{
Agronomic evaluation of Paspalum notatum Flügge under the influence of photoperiod
}

\author{
Juliana Medianeira Machado ${ }^{*}$, Miguel Dall'Agnol' ${ }^{2}$, Eder Alexandre Minski da Motta ${ }^{3}$, Emerson \\ André Pereira ${ }^{4}$, Carine Simioni², Roberto Luis Weiler ${ }^{2}$, Marcos Perera Zuñeda ${ }^{5}$, Priscila Becker \\ Ferreira $^{6}$
}

\footnotetext{
${ }^{1}$ Universidade de Cruz Alta, Centro de Ciências da Saúde e Agrárias, Cruz Alta, RS, Brazil.

2 Universidade Federal do Rio Grande do Sul, Faculdade de Agronomia, Departamento de Plantas Forrageiras e Agrometeorologia, Porto Alegre, RS, Brazil.

${ }^{3}$ Universidade Federal do Rio Grande do Sul, Programa de Pós-graduação em Zootecnia, Porto Alegre, RS, Brazil.

${ }^{4}$ Universidade Regional do Noroeste do Estado do Rio Grande do Sul, Departamento de Estudos Agrários, ljuí, RS, Brazil.

${ }^{5}$ Universidade Federal do Rio Grande do Sul, Faculdade de Agronomia, Porto Alegre, RS, Brazil.

${ }^{6}$ Universidade Federal do Pampa, Departamento de Tecnologia em Aquicultura, Uruguaiana, RS, Brazil.
}

\begin{abstract}
The objective of this study was to evaluate the influence of photoperiod on the forage yield by ecotypes and intraspecific hybrids of $P$. notatum. Tetraploid ecotypes from the United States Department of Agriculture and the National University of the Northeast in Argentina, in addition to six intraspecific hybrids, totaling 19 ecotypes, were assessed. The materials evaluated were subjected to an extended photoperiod ( $14 \mathrm{~h}$ of light) and natural photoperiod from July 2011 to October 2012. The experimental design was a completely randomized factorial scheme of $19 \times 2$ (ecotypes $\times$ photoperiod) consisting of five replicates. The materials were influenced differentially by the variation in photoperiod, with one group showing high sensitivity, whereas another, smaller group, was insensitive to this factor. The use of materials with differentiated responses to photoperiod in different climatic regions can be an important tool to increase forage yield of Paspalum notatum.
\end{abstract}

Key Words: ecotypes, forage yield, hybrids, subtropical grass

\section{Introduction}

The Brazilian livestock is largely raised under extensive systems, with pastures as the main source of feed for these herbivores. Brazil has a rich natural environment, with a diversity of species better adapted to local conditions than exotic species.

The genus Paspalum L. contains more than 400 tropical and subtropical species, whose importance is supported by adaptation to different ecosystems, representing a lower risk of biological imbalance because of existing genetic diversity (Strapasson et al., 2000). From a foraging point of view and given the large number of species present in the Pampa biome, these species are components of almost all

Received: May 23, 2016

Accepted: August 21, 2016

*Corresponding author: julianam.machado@yahoo.com.br

http://dx.doi.org/10.1590/S1806-92902017000100002

How to cite: Machado, J. M.; Dall'Agnol, M.; Motta, E. A. M.; Pereira, E. A.; Simioni, C.; Weiler, R. L.; Zuñeda, M. P. and Ferreira, P. B. 2017. Agronomic evaluation of Paspalum notatum Flügge under the influence of photoperiod. Revista Brasileira de Zootecnia 46(1):8-12.

Copyright (C) 2017 Sociedade Brasileira de Zootecnia. This is an Open Access article distributed under the terms of the Creative Commons Attribution License (http://creativecommons.org/licenses/by/4.0/), which permits unrestricted use, distribution, and reproduction in any medium, provided the original work is properly cited.
South Brazilian grasslands. Among these species, Paspalum notatum Flügge has good forage quality, high resistance to grazing and trampling by animals (Pozzobon and Valls, 1997), and was included in the PROBIO project of the Ministry of Environment (Brasil, 2009), among the so-called plants of the future, because of its potential to be introduced into the agricultural matrix.

However, its production is concentrated in the summer, with a drastic yield decline occurring during the winter. The dormancy induced by reduction of the photoperiod is the most important determining factor that negatively influences seasonal yield, in addition to the low temperatures occurring in this season (Sinclair et al., 2003). Thus, ecotypes or species considered sensitive to photoperiod display a decline in forage yield with the reduction of photoperiod, regardless of temperature.

The existence of intraspecific variability has aroused the interest of studies in selecting materials with higher forage yield and more adapted to different environmental conditions. Thus, crosses between sexual and apomictic ecotypes can be performed to obtain superior characters set by apomixis (Acuña et al. 2009).

To this end, assessments of genitors that have the capacity to convey traits of interest to their progeny are required, in addition to determining the genetic potential of 
hybrids from these crosses. The realization of agronomic field trials is important to provide a more precise and safe selection of these materials, which facilitates the indication for release as new commercial cultivations. Thus, the objective of this study was to evaluate the influence of photoperiod in the forage yield based on ecotypes and intraspecific hybrids of P. notatum.

\section{Material and Methods}

The experiment was conducted in Porto Alegre - RS,

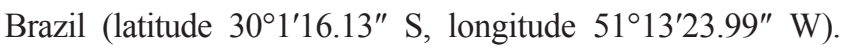
The photoperiod at this latitude varies from $10 \mathrm{~h}$ on June 21 to $14 \mathrm{~h}$ on December 21. The experiment was conducted from July 2011 to October 2012. The climate is classified as humid subtropical (Cfa) according to the Köppen classification (Moreno, 1961). We evaluated apomictic tetraploid ecotypes of Paspalum notatum Flügge from the United States Department of Agriculture (USDA), denominated $30 \mathrm{~N}, 36 \mathrm{~N}, 48 \mathrm{~N}, 70 \mathrm{~N}, 83 \mathrm{~N}, 95 \mathrm{~N}$, and $\mathrm{V} 4$, which were collected in South America, and sexual ecotypes from the National University of the Northeast in Argentina, denominated Q4188, Q4205, and C44X. In addition, we evaluated intraspecific hybrids of $P$. notatum resulting from crosses between the ecotypes Q4205 × André da Rocha (Progeny “C”) and Q4205 × Bagual (Progeny "D"), totaling six superior hybrids selected for production of total dry mass, denominated $\mathrm{C} 1, \mathrm{C} 2, \mathrm{C} 15, \mathrm{C} 17, \mathrm{D} 3$, and D16 (Table 1). The work was performed in this breeding program. The reproduction mode of the sexual genitors was

Table 1 - Identification of ecotypes and intraspecific hybrids of Paspalum notatum

\begin{tabular}{|c|c|c|}
\hline Ecotype & Identification & Ploidy level \\
\hline $30 \mathrm{~N}^{1}$ & Santa Fé - Argentina & Tetraploid \\
\hline $36 \mathrm{~N}^{1}$ & Santa Fé - Argentina & Tetraploid \\
\hline $48 \mathrm{~N}^{1}$ & Mercedes - Argentina & Tetraploid \\
\hline $70 \mathrm{~N}^{1}$ & Cordoba - Argentina & Tetraploid \\
\hline $83 \mathrm{~N}^{1}$ & Corrientes - Argentina & Tetraploid \\
\hline $95 \mathrm{~N}^{1}$ & Corrientes - Argentina & Tetraploid \\
\hline $\mathrm{V}^{1}{ }^{1}$ & Barra do Quarai/RS - Brazil & Tetraploid \\
\hline André da Rocha ${ }^{1}$ & André da Rocha/RS - Brazil & Tetraploid \\
\hline Bagual $^{1}$ & Missões/RS - Brazil & Tetraploid \\
\hline Pensacola ${ }^{1}$ & Viamão/RS - Brazil & Diploid \\
\hline $\mathrm{C} 44 \mathrm{x}^{2}$ & Corrientes - Argentina & Tetraploid \\
\hline Q4188² & Corrientes - Argentina & Tetraploid \\
\hline Q4205² & Corrientes - Argentina & Tetraploid \\
\hline $\mathrm{C} 1^{3}$ & Porto Alegre/RS - Brazil & Tetraploid \\
\hline $\mathrm{C} 2^{3}$ & Porto Alegre/RS - Brazil & Tetraploid \\
\hline $\mathrm{C} 15^{3}$ & Porto Alegre/RS - Brazil & Tetraploid \\
\hline $\mathrm{C} 17^{3}$ & Porto Alegre/RS - Brazil & Tetraploid \\
\hline D3 $3^{3}$ & Porto Alegre/RS - Brazil & Tetraploid \\
\hline D16 $6^{3}$ & Porto Alegre/RS - Brazil & Tetraploid \\
\hline
\end{tabular}

\footnotetext{
${ }^{1}$ Obtained by field collections.

${ }^{2}$ Obtained through chromosome duplication in the laboratory.

${ }^{3}$ Obtained through intraspecific crosses of Paspalum notatum.
}

described by Quarin et al. (2001) and the ploidy level of the other ecotypes was analyzed by Fachinetto et al. (2012). Paspalum notatum 'Pensacola' and two native ecotypes of Rio Grande do Sul, denominated André da Rocha and Bagual, collected in the 1980 s, were used as sources. The apomictic ecotypes have gone through a selection process for production of total dry mass (Fachinetto et al., 2012). Five clones of each ecotype were prepared, placed in 2.8-L pots with a commercial substrate, and placed in an open area where they were subjected to natural and extended photoperiods (14-h light) between July and August 2011 and from March to August 2012. Four 250-W metal halide lamps were placed $1.5 \mathrm{~m}$ from the plants in the extended photoperiod treatment. We used a light meter to measure the light intensity received by the plants subjected to the extended photoperiod. As different light intensities were detected, the plants were reallocated every three days. The experimental design was completely randomized in a $19 \times 2$ (ecotypes $\times$ photoperiod) factorial design with extended and natural photoperiod consisting of five replicates. The total dry weight yield of the ecotypes was evaluated by cutting, resulting in twelve cuts during the evaluation period. The cuts were performed when ecotypes and hybrids reached an average height of $15 \mathrm{~cm}$ and a $5-\mathrm{cm}$ height residue was maintained. The collected materials were placed to dry in a greenhouse with forced air at $65{ }^{\circ} \mathrm{C}$ for $72 \mathrm{~h}$ and were subsequently weighed. The data were subjected to analysis of variance (ANOVA) with F test and comparison of means was performed with the Scott-Knott and Tukey tests at 5\% significance, using the GENES software (Cruz, 2007). We also performed a Pearson's correlation analysis among seasons.

\section{Results and Discussion}

There was an interaction between ecotypes $\times$ photoperiod $(\mathrm{P}<0.05)$ for the productivity of total dry mass (PTDM) $\left(\mathrm{g}\right.$ pot $^{-1}$ ), with the formation of distinct groups that demonstrated the existence of genetic variability between the evaluated ecotypes (Tables 2 and 3 ). The reduction in forage yield of Paspalum notatum in the winter period characterized it as a long-day species (Newman et al., 2007), which flowers between the months of October and March, and approximately $85 \%$ of forage yield occurs during summer (Newman et al., 2011). Thus, the key issue for this type of response is whether an extended photoperiod during the cold months could have a negative impact on subsequent yields of ecotypes and hybrids, while resulting in an increase in forage yield during the cold months. A potential use of the reserve substances stored in 
the rhizomes could be to promote changes in forage yield during the favorable growth season for the species.

From the results of the experiment, it was possible to classify the materials evaluated as sensitive or insensitive to photoperiod. Published reports state that the earlier a species expresses its growth potential, the lower its sensitivity to photoperiod will be (Rosa et al., 2009), and consequently the reduction of the vegetative period will be lower (Garner and Allard, 1920).

Regarding the regrowth capacity during the transition from winter to spring, in the first year of evaluation, the ecotypes demonstrated rapid regrowth under both treatments (Table 2). Among the 19 materials tested, 17 showed no differences in PTDM in the transition from winter to spring when subjected to the extended photoperiod. This response did not hamper growth in the subsequent spring season, which was confirmed by the positive correlation between the two seasons $(r=0.73 ; \mathrm{P}=0.0004)$. Only the $\mathrm{C} 2$ and $\mathrm{D} 3$ hybrids had lower PTDM in spring when subjected to the extended photoperiod. The results could indicate that these materials consumed their energy reserves during winter, which may have affected the forage yield in the subsequent season.

The ecotype Q4205 stood out when subjected to extended photoperiod and had the highest numerical PTDM in spring; however, this ecotype was not in the most productive group during the winter season. When subjected to natural photoperiod, there was a rapid regrowth and

Table 2 - Yield of total dry mass of Paspalum notatum ecotypes in different environments and seasons

\begin{tabular}{|c|c|c|c|c|}
\hline \multirow{3}{*}{ Ecotype } & \multicolumn{4}{|c|}{ Year 1} \\
\hline & \multicolumn{2}{|c|}{ Extended photoperiod } & \multicolumn{2}{|c|}{ Natural photoperiod } \\
\hline & Winter & Spring & Winter & Spring \\
\hline $30 \mathrm{~N}$ & $\mathrm{~A} 1.2 \mathrm{ab}$ & A11.8def & B0.6abcde & A9.4cdef \\
\hline $36 \mathrm{~N}$ & A $0.7 \mathrm{bcd}$ & A9.3ef & A0.5abcde & A7.3ef \\
\hline $48 \mathrm{~N}$ & A0.6bcd & A12.0def & A0.8abcde & A9.9cde \\
\hline $70 \mathrm{~N}$ & A0.9bcd & A13.6cdef & B0.3bcde & B8.1def \\
\hline $83 \mathrm{~N}$ & A0.6bcd & A9.0f & A0.7abcde & A8.5def \\
\hline $95 \mathrm{~N}$ & $\mathrm{~A} 0.9 \mathrm{bc}$ & A11.1def & A0.7abcde & A11.1bcde \\
\hline V4 & A0.7bcd & A12.7cdef & B0.3cde & A9.4cdef \\
\hline André da Rocha & A1.8a & A11.3def & A1.0abcd & A8.9def \\
\hline Bagual & A1.3ab & A12.1cedef & A0.7abcd & B9.8cde \\
\hline Pensacola & A1.1ab & A10.9def & B0.2e & B3.5f \\
\hline Q4188 & A1.1ab & A18.0b & A1.1a & B9.5cde \\
\hline Q4205 & A0.8bcd & A23.1a & A1.0ab & B9.9cde \\
\hline C44X & A $0.7 \mathrm{bcd}$ & A9.8ef & B0.4cde & A8.7def \\
\hline $\mathrm{C} 1$ & A0.7bcd & A13.7bcdef & A $0.4 \mathrm{abcde}$ & A18.0ab \\
\hline $\mathrm{C} 2$ & $\mathrm{~A} 0.3 \mathrm{~cd}$ & B11.1def & B0.1e & A15.0abc \\
\hline $\mathrm{C} 15$ & $\mathrm{~A} 0.3 \mathrm{~cd}$ & A16.9bc & $\mathrm{B} 0.2 \mathrm{e}$ & A18.6a \\
\hline $\mathrm{C} 17$ & $\mathrm{~A} 0.2 \mathrm{~d}$ & A14.9bcd & $\mathrm{A} 0.2 \mathrm{e}$ & B10.4bcde \\
\hline D3 & A0.6bcd & B17.7b & A1.0abc & A19.1a \\
\hline D16 & A0.6bcd & A13.9bcde & B0.3de & A13.3abcd \\
\hline
\end{tabular}

Means preceded by different uppercase letters in the row differ between seasons within the year by the Scott-Knott test $(\mathrm{P}<0.05)$ and means followed by different lowercase letters in the column differ by the Tukey test $(\mathrm{P}<0.05)$. accumulation of dry mass of hybrids in the spring season, when compared with genitors Q4205 × André da Rocha and Q4205 × Bagual, maximizing the benefits obtained by hybrid vigor (Carvalho et al., 2001). The genetic variability observed in the evaluated materials creates a substantial opportunity to perform new crosses within the breeding program. Thus, the best hybrids with regrowth capacity in spring could be used as male genitors in crosses with female genitors that have high forage yield, which could make it possible to obtain new elite recombinants to use in different environments.

Thus, when hybridization is performed between sexual and apomictic plants, there will be segregation for apomixis and sexuality in the next generation. The apomictic progenies, which present the desired agronomic traits, could be subjected to the final stages of evaluation for later release as new cultivars. On the other hand, sexual plants with superior characteristics could be used in new recombinations within the breeding program (Burton et al., 1973; Jank et al., 2011).

In the second year of assessment, there were variations with respect to regrowth of ecotypes in the transition period between winter and spring (Table 3). The ecotypes Q4188 and Q4205 had higher PTDM in spring, with increases of 1.3- and 1.4-fold, respectively. The other ecotypes, 30N, 36N, V4, C44X, C2, C15, C17, D3, and D16, also had good regrowth capacity; however, the intensity of response was relatively low. On the other hand, the ecotypes $70 \mathrm{~N}$ and $83 \mathrm{~N}$ had similar PTDM during this evaluation period. The ecotypes $48 \mathrm{~N}, 95 \mathrm{~N}$, André da Rocha, Bagual, C1, and the cultivar Pensacola exhibited decreases in this parameter, displaying slower regrowth after winter.

There was variation in PTDM when the ecotypes were subjected to natural photoperiod. The majority of ecotypes presented the highest yields in spring, with the exception of ecotype $30 \mathrm{~N}$, which displayed the opposite behavior. The hybrid $\mathrm{C} 1$ and the cultivar Pensacola displayed similar yields in winter and spring.

In the second year of assessment, the productive superiority of hybrids compared with genitors was again apparent, which indicated the expression of their genetic potential after establishment. According to Pereira et al. (2002), in the year of establishment for young plants, only part of the genes responsible for traits of interest may be expressed, whereas in the adult stage, the full potential of the plant is expressed, resulting in changes in the phenotype. The cultivar Pensacola is one of the few alternative seeds of summer-cultured species available for sale in southern Brazil. Therefore, it is important to note that the native ecotypes showed greater development in 
the beginning of the warm season when compared with the commercial cultivars, pointing to the need to exploit the productive potential of these materials. It is important that the highlighted materials in this study be directed to field trials to check their yield potential, persistence, and adaptation to different climatic conditions, as well as resistance to pathogens and diseases.

When the transition period between summer and autumn was analyzed, the ecotypes André da Rocha, Bagual, and the cultivar Pensacola exhibited pronounced reductions in PTDM of approximately 4.1-, 4.2-, and 2.4fold, respectively, when subjected to natural photoperiod (Table 3). It should be noted that the tested hybrids exhibited lower or similar reduction in PTDM observed for the cultivar Pensacola, which displayed a lower growth reduction with shorter photoperiod, but had a low-yield potential.

The availability of variability in response to photoperiod is extremely important in any breeding program for forage species. This characteristic can provide a reduction in the forage deficit present in the southern region of Brazil caused by the transition period between the seasons.

There was no variation in the PTDM of ecotypes $36 \mathrm{~N}, 48 \mathrm{~N}$, and $83 \mathrm{~N}$ during all seasons, regardless of the photoperiod and year of assessment (Tables 2 and 3). This information suggests a greater stability of these ecotypes compared with the others and they can be classified as insensitive to photoperiod reduction, maintaining a stable yield throughout the seasons. This feature could assist in the selection process of ecotypes with greater seasonal distribution of forage yield, depending on the region in which they will be used. The results of PTDM do not serve as indicators of the behavior of the forage yield throughout the seasons and, consequently, PTDM cannot be used as the sole factor of choice of species or cultivar to be adopted.

Some of the factors that affect the physiology of forage plants are climatic factors, such as photoperiod and temperature (Whiteman, 1980). The identification of materials described as insensitive is important, as these could be used in regions with milder weather, where the decrease in yield occurs mainly because of the photoperiod in the winter season. The results obtained suggested that the male genitors could be used in schemes of intraspecific crosses with female genitor ecotypes with sexual reproduction and high forage yield during the seasons that favor their growth.

Thus, although the ecotypes Q4188 and Q4205 presented intermediate PTDM in the summer season when subjected to natural photoperiod, the fact that they presented a sexual reproduction mode makes them eligible as female genitors for crosses with the ecotypes $36 \mathrm{~N}, 48 \mathrm{~N}$, and $83 \mathrm{~N}$. Hence, the progenies of the ecotype Q4188 could be used in environments with mild winters. On the other hand, within the possibilities of sexual materials available in the breeding program, the ecotype Q4205 could be used in crosses for environments with colder winters. It is also

Table 3 - Yield of total dry mass of Paspalum notatum ecotypes in different environments and seasons

\begin{tabular}{|c|c|c|c|c|c|c|c|c|}
\hline \multirow{3}{*}{ Ecotype } & \multicolumn{8}{|c|}{ Year 2} \\
\hline & \multicolumn{4}{|c|}{ Extended photoperiod } & \multicolumn{4}{|c|}{ Natural photoperiod } \\
\hline & Summer & Autumn & Winter & Spring & Summer & Autumn & Winter & Spring \\
\hline $30 \mathrm{~N}$ & A17.1cde & A7.5bcd & A5.2bcd & A $5.5 b c$ & A16.8cdef & B4.8cde & A4.6b & A4.1cd \\
\hline $36 \mathrm{~N}$ & A18.2bcde & A6.3bcd & A4.9bcde & A $5.5 \mathrm{~cd}$ & A16.2cdef & A5.1cde & A $2.7 b c$ & A $3.7 \mathrm{cde}$ \\
\hline $48 \mathrm{~N}$ & A17.3cde & A8.5bc & A4.6bcde & $\mathrm{A} 4.3 \mathrm{~cd}$ & A18.3bcde & A4.8cde & A $3.3 b c$ & A $5.0 \mathrm{bcd}$ \\
\hline $70 \mathrm{~N}$ & A17.5bcde & A9.4b & A5.3bcd & A $5.2 \mathrm{~cd}$ & B12.6defg & B3.3e & $\mathrm{B} 2.2 \mathrm{bc}$ & B3.3de \\
\hline $83 \mathrm{~N}$ & A9.5f & $\mathrm{A} 4.2 \mathrm{~cd}$ & A4.9bcde & A4.8cd & A12.1defg & A3.4de & $\mathrm{A} 1.5 \mathrm{c}$ & A $3.7 \mathrm{cde}$ \\
\hline $95 \mathrm{~N}$ & A17.5bcde & A9.2b & A6.8bcd & A6.5bcd & A18.5bcde & A8.0abc & B3.8bc & B4.9bcd \\
\hline V4 & A18.8bcde & A8.5bc & A3.6de & A4.6cd & A16.1cdef & A5.7bcde & $\mathrm{A} 2.8 \mathrm{bc}$ & A4 $4.3 \mathrm{bcd}$ \\
\hline André da Rocha & A18.5bcde & A9.0b & A6.3bcd & A $5.3 \mathrm{~cd}$ & B10.6efg & B2.6e & $\mathrm{B} 2.2 \mathrm{bc}$ & A3.1de \\
\hline Bagual & A19.0bcd & A7.9bc & A6.8bcd & A $5.4 \mathrm{~cd}$ & A18.5cde & B4.4cde & B3.3bc & A4.0cde \\
\hline Pensacola & A11.8ef & A4.5cd & A4.0cde & A3.7cd & B6.4g & B2.7e & A1.9bc & $\mathrm{A} 2.0 \mathrm{e}$ \\
\hline Q4188 & A33.2a & $\mathrm{A} 14.0 \mathrm{a}$ & A7.7ab & $\mathrm{A} 10.5 \mathrm{ab}$ & $\mathrm{B} 22.8 \mathrm{bc}$ & B8.0abc & B3.3bc & B5.6bc \\
\hline Q4205 & $\mathrm{A} 24.4 \mathrm{~b}$ & A $8.5 b c$ & A7.5abc & $\mathrm{A} 12.4 \mathrm{a}$ & B16.3cdef & B3.1e & B2.6bc & B3.9cde \\
\hline C44X & A13.6def & A3.1d & $\mathrm{A} 1.5 \mathrm{e}$ & A $3.4 d$ & A9.3fg & A2.6e & $\mathrm{A} 1.4 \mathrm{c}$ & $\mathrm{A} 3.1 \mathrm{e}$ \\
\hline $\mathrm{C} 1$ & A20.0bcd & A9.0b & $\mathrm{A} 11.2 \mathrm{a}$ & $\mathrm{A} 10.54 \mathrm{ab}$ & $\mathrm{A} 21.7 \mathrm{bc}$ & A6.2bcde & B7.8a & B8.0a \\
\hline $\mathrm{C} 2$ & B14.2def & A7.6bcd & A3.9cde & $\mathrm{A} 5.3 \mathrm{~cd}$ & A19.3bcd & A7.6abc & A $3.4 b c$ & A4.8bcd \\
\hline C15 & $\mathrm{A} 22.6 \mathrm{bc}$ & $\mathrm{A} 10.7 \mathrm{ab}$ & A5.2bcd & A $5.8 \mathrm{~cd}$ & $\mathrm{~A} 25.5 \mathrm{ab}$ & A9.6ab & A4 6 b & A5.7bc \\
\hline $\mathrm{C} 17$ & A15.9cdef & A9.7ab & A4.8bcde & A $5.5 \mathrm{~cd}$ & A20.1bcd & B7.5abcd & B2.5bc & A $5.0 \mathrm{bcd}$ \\
\hline D3 & B19.4bc & A10.6ab & A5.5bcd & A6.2cd & A32.3a & A10.9a & B3.6bc & B5.1bcd \\
\hline D16 & A16.9cde & A7.6bcd & A5.9bcd & A7.5bc & A19.1bcd & A8.5abc & $\mathrm{A} 4.2 \mathrm{bc}$ & A6.3ab \\
\hline
\end{tabular}

Means preceded by different uppercase letters in the row differ between seasons within the year by the Scott-Knott test ( $<<0.05)$ and means followed by different lowercase letters in the column differ by the Tukey test $(\mathrm{P}<0.05)$. 
worth noting that the presence of responsive materials is important for areas with colder climates, because this mechanism probably acts as a defense mechanism against an unfavorable season for its development.

Sinclair et al. (2001) pointed out that the selection of photoperiod-insensitive ecotypes could substantially increase forage yield in subtropical regions. The limited forage availability during the months with shorter day length has been one of the most important factors influencing animal production and the pasture management (Sinclair et al. 2003), although it cannot be used as a single parameter responsible for the low-forage yield during this period. Newman et al. (2007), in a study conducted in Florida with the genera Paspalum, Panicum and Cynodon, observed average yields of total dry mass 3.5 times higher with extended photoperiod when compared with the normal photoperiod that occurs during the winter.

Further studies with the goal of obtaining new crosses between elite recombinants may contribute to the achievement of progenies adapted to different climatic conditions, in which the photoperiod has an extreme influence on forage yield. Thus, the quest for sexual materials that are the source of variability in apomictic species is of utmost importance, because it can fix this characteristic within the breeding program and will contribute to a better distribution of forage throughout the year, reducing the forage deficit that occurs in subtropical regions.

\section{Conclusions}

The materials were influenced differentially by the variation in the photoperiod, with one group with great sensitivity, whereas a smaller group exhibited insensitivity to this factor. The use of materials with different responses to photoperiod in different climatic regions can be an important tool for increasing the forage yield of Paspalum notatum.

\section{References}

Acuña, C. A.; Blount, A. R.; Quesenberry, K. H.; Kenworthy, K. E. and Hanna, W. W. 2009. Bahiagrass tetraploid germplasm: reproductive and agronomic characterization of segregating progeny. Crop Science 49:581-588.
Brasil. Ministério do Meio Ambiente. 2009. Projeto plantas para o futuro. Available at: <http:www.mma.gov.br $>$. Accessed on: Apr. 10, 2013.

Burton, G. W.; Millot, J. C. and Monson, W. G. 1973. Breeding procedures for Panicum maximum Jacq. suggested by plant variability and mode of reproduction. Crop Science 13:717-720.

Carvalho, F. I. F.; Silva, S. A.; Kurek, A. J. and Marchioro, V. S. 2001. Estimativas e implicações da herdabilidade como estratégia de seleção. UFPel, Pelotas.

Cruz, C. D. 2007. Programa Genes: aplicativo computacional em genética e estatística. UFV, Viçosa, MG.

Fachinetto, J. M.; Schneider, R.; Hubber, K. G. C. and Dall'Agnol, M. 2012. Avaliação agronômica e análise da persistência em uma coleção de acessos de Paspalum notatum Flügge (Poaceae). Revista Brasileira de Ciências Agrárias 7:189-195.

Garner, W. W. and Allard, H. A. 1920. Effect of the relative length of day and night and other factors of the environment on growth and reproduction in plants. Journal of Agricultural Research 18:553-606.

Jank, L.; Valle, C. B. and Resende, R. M. S. 2011. Breeding tropical forages. Crop Breeding and Applied Biotechnology 11:27-34.

Moreno, J. A. 1961. Clima do Rio Grande do Sul. Secretaria da Agricultura, Porto Alegre.

Newman, Y. C.; Sinclair, T. R.; Blount, A. S.; Lugo, M. L. and Valencia, E. 2007. Forage production of tropical grasses under extended day length at subtropical and tropical latitudes. Environmental and Experimental Botany 61:18-24.

Newman, Y. C.; Vendramini, J. and Blount, A. 2011. Bahiagrass (Paspalum notatum): Overview and management. Fact Sheet SS-AGR-332. University of Florida Cooperative Extension Service, IFAS, University of Florida, Gainesville, FL. Available at: $<$ http://edis.ifas.ufl.edu/ag342>. Accessed on: Aug. 15, 2015.

Pereira, A. V.; Cruz, C. D.; Ferreira, R. P.; Botrel, M. A. and Oliveira, J. S. 2002. Influência da estabilização de genótipos de capimelefante (Pennisetum purpureum Schum.) sobre a estimativa da repetibilidade de características forrageiras. Ciência e Agrotecnologia 26:762-767.

Pozzobon, M. T. and Valls, J. M. 1997. Chromosome number in germplasm accessions of Paspalum notatum (Gramineae). Brazilian Journal of Genetic 20:29-34.

Quarin, C. L.; Espinoza, F.; Martinez, E. J.; Pessino, S. C. and Bovo, O. A. 2001. A rise of ploidy level induces the expression of apomixis in Paspalum notatum. Sexual Plant Reproduction 13:243-249.

Rosa, H. T.; Walter, L. C.; Streck, N. A. and Alberto, C. M. 2009. Métodos de soma térmica e datas de semeadura na determinação de filocrono de cultivares de trigo. Pesquisa Agropecuária Brasileira 44:1374-1382.

Sinclair, T. R.; Mislevy, P. and Ray, J. D. 2001. Short photoperiod inhibits winter growth of subtropical grasses. Plant 213:488-491.

Sinclair, T. R.; Ray, J. D.; Mislevy, P. and Premazzi, M. 2003. Growth of subtropical forage grasses under extended photoperiod during short-day length months. Crop Science 43:618-623.

Strapasson, E.; Vencovsky, R. and Batista, L. A. R. 2000. Seleção de descritores na caracterização de germoplasma de Paspalum sp. por meio de componentes principais. Revista Brasileira de Zootecnia 29:373-381.

Whiteman, P. C. 1980. Tropical pasture science. Oxford University Press, New York. 